\title{
Effects of Enalapril and Captopril on Urinary Excretion of Kinins and Electrolytes in Stroke-Prone Spontaneously Hypertensive Rats
}

\author{
Koichiro KAWASHIMA, Miyako KIMURA, Takushi X. WATANABE*, \\ Hirofumi SOKABE* and Yuji KOBAYASHI** \\ Department of Pharmacology. Kyoritsu College of Pharmacy. Minato-ku. \\ Tokyo 105. Japan \\ *Department of Pharmacology. Jichi Medical School. Tochigi-ken 329-04. Japan \\ **Special Reference Laboratory, Hachioji, Tokyo 192, Japan
}

Accepted September 4.1985

\begin{abstract}
Urinary excretion of kinins in stroke-prone spontaneously hypertensive (SHRSP) rats was unchanged during oral enalapril $(10 \mathrm{mg} / \mathrm{kg}$ ) or captopril (30 $\mathrm{mg} / \mathrm{kg}$ ) treatment once a day for 8 days compared to vehicle treatment. However, a significant decrease in urinary kinin excretion was observed on the 5th and 7th day compared to the pretreatment value in rats treated with enalapril. Both enalapril and captopril produced a significant reduction in blood pressure when compared to the vehicle. These findings provide no positive evidence to support the hypothesis of possible involvement of renat kinins in the antihypertensive effect of converting enzyme inhibitors in SHRSP rats.
\end{abstract}

The mechanism of the antihypertensive action of orally active converting enzyme (CE) inhibitors such as captopril and enalapril is a matter of dispute (1). CE has been shown to be identical with kininase II (2). Therefore, its inhibition may lead to reduction in both generation of angiotensin (ANG) $\|$ and degradation of kinins. Increase in urinary kinin excretion in dogs treated with captopril has raised the possibility that in addition to the reduced formation of ANG II, the accumulation of hypotensive vasodilator kinins in the kidney could also contribute to the antihypertensive effect of CE inhibitors (3-5). However. McCaa (6) has reported that the reduction in blood pressure induced by captopril can be reversed by infusion of ANG II, even in the presence of increased urinary kinin excretion, suggesting that the hypotensive action of captopril is due to the inhibition of ANG II formation and not to the accumulation of kinins. To investigate the possible involvement of renal kinins in the antihypertensive effect of $C E$ inhibitors. we determined the urinary excretion of kinins and electrolytes in stroke-prone spontaneously hypertensive (SHRSP) rats during treatment with enalapril and captopril. We have previously demonstrated that plasma renin activity in SHRSP rats is elevated during the late developmental and maintenance stage of hypertension $(7,8)$ and that CE inhibitors produce a marked antihypertensive effect and prevent develooment of malignant hypertensive cardiovascular diseases in this hypertensive model $(9,10)$

Twelve-week-old male SHRSP rats from the colony maintained at the Department of Pharmacology, Jichi Medical School were used for the study. They were housed in individual metabolism cages (KN 646 . Natsume) with water and powdered rat chow (MR-3-A. Nosan) offered ad libitum. Enalapril and captopril were dissolved in distilled water and administered once a day for 8 days by gavage at doses of 10 and 30 $\mathrm{mg} / \mathrm{kg}$ per day, respectively. Control animals were treated with only the vehicle. Blood pressure was measured by the tail-cuff method (KN-210. Natsume) before and on 
the 8 th day of the experiment. Twenty-fourhr urine samples were collected before, and on the 1 st. $3 \mathrm{rd}$. 5 th and 7 th days of treatment into a graduated cylinder containing $100, \mathrm{n}$ of $6 \mathrm{~N} \mathrm{HCl}$ and $20 \% \mathrm{~g}$ of pepstatin $\mathrm{A}$ to inhibit kinin formation during the collection. Urinary excretion of kinins was determined by a radioimmunoassay (11). Urinary excretion of sodium $\left(U_{\mathrm{N}_{n}} V\right)$ and potassium $\left(U_{K} V\right)$ was measured with a flame photometer (model 343, Instrumentation Laboratory). Means and standard errors are presented in the figure and table. Scheffe's $S$-test was used to detect significant differences among the experimental groups. Fisher's least significant difference method was used for comparison of the daily changes in urinary excretion of these components within groups.

The blood pressure in SHRSP rats treated with enalapril or captopril for 8 days was significantly lower than that in animals treated with vehicle (192 \pm 2 and $207 \pm 7$ vs. $248 \pm 4 \mathrm{mmHg}) \quad(P<0.01)$. The antihypertensive potency of these $C E$ inhibitors in SHRSP rats is compatible with that found in our previous study $(10)$.

Urinary excretion of kinins during treatment with CE inhibitors is shown in Fig. 1. Because of large interindividual variations, no significant differences were observed among the groups. However, in enalapril treated rats, urinary kinin excretion was significantly decreased on the 5th and 7 th days when compared with the pretreatment value $(P<$ 0.05 ). In a previous study in 14 to 15 -weekold SHRSP rats, we found significant decreases in urinary excretion of kinins and urine volume (UV) in the 5th and 10th weeks of treatment with both enalapril and captopril (10). However, the data on urinary kinin excretion were not included in the paper because we collected acidified urine samples without pepstatin $A$, and the possibility of kinin formation during urine collection could not be excluded. A significant reduction in blood pressure in the presence of unchanged or perhaps decreased urinary kinin excretion during treatment with enalapril and captopril does not appear to

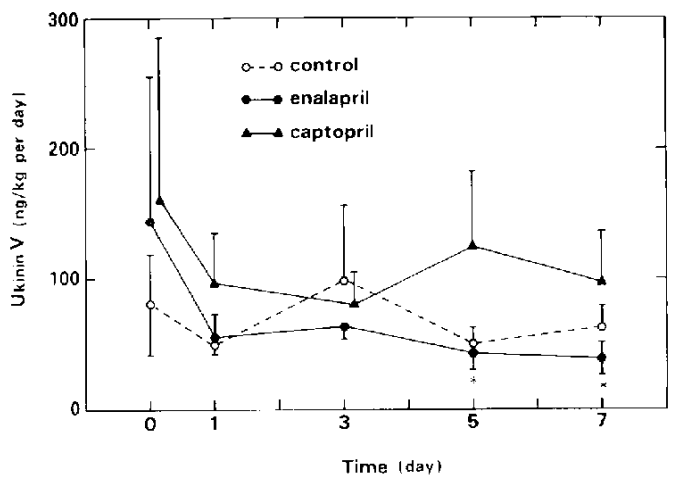

Fig. 1. Effect of enalapril and captopril on urinary excretion of kinins in SHRSP rats. "P<0.05, compared to the pretreatment value.

Table 1. Effects of enalapril and captoprit on urine volume, and urinary excretion of sodium and potassium

\begin{tabular}{|c|c|c|c|c|c|}
\hline Treatment & 0 & 1 & 3 & 5 & 7 day \\
\hline & \multicolumn{5}{|c|}{ Urine volume ( $\mathrm{ml} / \mathrm{kg}$ per day) } \\
\hline Control (6) & $43.3 \pm 7.8$ & $45.4 \pm 8.2$ & $41.8 \pm 6.8$ & $46.0 \pm 8.0$ & $44.2 \pm 5.9$ \\
\hline Enalapril (5) & $39.0 \pm 7.7$ & $41.7 \pm 7.9$ & $43.7 \pm 3.1$ & $41.0 \pm 3.1$ & $38.8 \pm 5.4$ \\
\hline \multirow[t]{2}{*}{ Captopril (5) } & $48.7 \pm 12.0$ & $47.1 \pm 11.2$ & $41.2 \pm 9.4$ & $40.0 \pm 4.7$ & $42.2 \pm 4.4$ \\
\hline & \multicolumn{5}{|c|}{$U_{N a} V(m E q / k g$ per day $)$} \\
\hline Control $(6)$ & $4.9 \pm 1.1$ & $5.8 \pm 0.9$ & $5.8 \pm 0.9$ & $5.2 \pm 0.6$ & $5.3 \pm 0.5$ \\
\hline Enalapril (5) & $4.5 \pm 0.9$ & $6.2 \pm 0.5^{*}$ & $6.2 \pm 0.6^{*}$ & $5.7 \pm 0.4$ & $5.4 \pm 0.2$ \\
\hline \multirow[t]{2}{*}{ Captopril (5) } & $6.9 \pm 0.8$ & $6.2 \pm 0.5$ & $5.4 \pm 1.3$ & $3.9 \pm 0.7^{* *}$ & $5.1 \pm 0.7$ \\
\hline & \multicolumn{5}{|c|}{$U_{\mathrm{H}} V(m E q / k g$ per day $)$} \\
\hline Control (6) & $11.3 \pm 1.4$ & $12.3 \pm 0.9$ & $11.3 \pm 0.8$ & $11.1 \pm 0.8$ & $11.3 \pm 0.5$ \\
\hline Enalapril (5) & $11.7 \pm 0.9$ & $12.0 \pm 0.8$ & $12.5 \pm 0.4$ & $12.1 \pm 0.8$ & $12.1 \pm 0.7$ \\
\hline Captopril (5) & $12.6 \pm 0.5$ & $11.7 \pm 0.5$ & $10.7 \pm 2.0$ & $10.3 \pm 1.4$ & $11.5 \pm 1.3$ \\
\hline
\end{tabular}

Number of animals is shown in the parenthesis. ${ }^{*} P<0.05 .{ }^{* *} P<0.01$, compared to the pretreatment value (day 0 ). 
favor a hypothesis of direct participation of renal kinins in the antihypertensive effect of these CE inhibitors in SHRSP rats.

Effects of enalapril and captopril on urinary excretion of electrolytes are shown in Table 1. Among the experimental groups, no significant differences in UV, $U_{\kappa_{n}} V$ and $U_{k} V$ were observed before or during treatment with CE inhibitors. In rats treated with enalapril, a significant increase in $U_{\mathrm{Na}_{a}} V$ was observed on the 1 st and 3rd days when compared to the pretreatment value $(P<0.05)$. On the other hand. $U_{\mathrm{Na}} \vee$ was decreased on the 5 th day in rats treated with captopril when compared to the pretreatment value $(P<0.01)$. Acute increase in urinary electrolyte excretion has been reported in SHR rats treated with captopril at a dose of $100 \mathrm{mg} / \mathrm{kg}$. but not at $30 \mathrm{mg} / \mathrm{kg} \mathrm{(12).}$ Because both enalapril and captopril produced a marked reduction in blood pressure, the transient effect on electolytes excretion produced by CE inhibitors might not be directly related to their long-term antihypertensive action.

\section{References}

1 Sweet, C.S. and Blaine, E.H.: Angiotensinconverting enzyme inhibitors. In Pharmacology of Anthypertensive Drugs, Edited by van Zwieten. P.A. p. 343-363, Elsevier. Amsterdam (1984)

2 Yang, H.Y.T., Erdos, E.G. and Levin, Y.: A dipeptidyl carboxypeptidase that converts angio tensin 1 and inactivates bradykinin. Biochim. Biophys. Acta 214, 374-376 (1970)

3 Yoshinaga, K., Abe, K., Miwa, I., Furuyama, T. and Suzuki, C.H.: Evidence for the renal origin of urinary kinin. Experientia 20, 396-397 (1965)

4 Johnston, C.l., Clappison, B.H., Anderson, W.P. and Yasujima, $M$ : Effect of angiotensinconverting enzyme inhibition on circulating and local kinin levels. Am. J. Cardiol. 49, 1401 1404 (1982)

5 Olsen, U.B. and Arrigoni-Martelli, E.: The effects of kininase $\mid$ in inhibition by SO 14225 on kidney kallikrein-kinin and prostaglandin systems in conscious dogs. Eur. J. Pharmacol. 54, 229-234 (1979)

6 McCaa, R.E.: Studies in vivo with antiotensin I converting enzyme (kininase 11 ) inhibitors. Fed. Proc. 39, 2783-2787 (1979)

7 Kawashima, K., Shiono, K. and Sokabe, H.: Renal and plasma renin activity and renal sodium and water excretion in stroke-prone and other substrains of spontaneously hypertensive rats. Japan. Heart J. 20, Supp. 1, 159-161 (1979)

8 Kawashima, K., Shiono, K. and Sokabe, $H$.: Variation of plasma and kidney renin activities among substrains of spontaneously hypertensive rats. Clin. Exp. Hyper. 2, 229-245 (1980)

9 Watanabe, T.X., Kawashima, K., Saito, K. and Sokabe, H.: Effects of long-term treatments with captopril on blood pressure and renin activity in the stroke-prone spontaneously hypertensive rats. Japan. J. Pharmacol. 30, 819-827 (1980)

10 Watanabe, T.X., Kawashima, K. and Sokabe, H.: Chronic effects of enalapril on blood pressure. stroke, plasma renin, urimary electrolytes and $\mathrm{PGE}_{2}$ excretion in the stroke-prone spontaneously hypertensive rats. Japan. J. Pharmacol. 38, 419-427 (1985)

11 Shimamoto, K., Ando, T., Nakao, T., Tanaka, S., Sakuma, $M$. and Miyahara, M.: A sensitive radioimmunoassay method for urinary kinins in man. J. Lab. Clin. Med. 91, 721-728 (1978)

12 Miyamoto, M., Koike, H., Ito, K. and Yamazaki, $M$ : Effects of captopril on urinary excretion of prostaglandins and electrolytes in spontaneously hypertensive rats. Eur. J. Pharmacol. 76, 187-192 (1981) 